\title{
A Structured Selection Process for Small and Medium Enterprises in Construction Industry: Case of International Projects
}

\author{
Serdar Ulubeyli', Aynur Kazaz ${ }^{2}$, Volkan Arslan' \\ ${ }^{1}$ Department of Civil Engineering,Bulent Ecevit University \\ ${ }^{2}$ Department of Civil Engineering, Akdeniz University
}

\begin{tabular}{l} 
Article Info \\
\hline Article history: \\
Received May $16^{\text {th }}, 2017$ \\
Revised Aug $18^{\text {th }}, 2017$ \\
Accepted Oct $18^{\text {th }}, 2017$ \\
\hline
\end{tabular}

\section{Keyword:}

Construction projects International projects Selection criteria Small and medium enterprise Subcontractor Sustainability

\begin{abstract}
Construction industry in most countries relies heavily on small and medium enterprises (i.e., subcontractors). Therefore, in today's highly competitive construction business, it is inevitable to select suitable subcontractors which physically execute almost all of production activities in construction projects. In this context, through a proper selection process, their competences should be guaranteed as much as possible. In fact, this becomes a more significant issue if the project undertaken is performed abroad. In this regard, it should be noted that Turkish construction companies have been significantly active in the international arena for decades. Based on these arguments, subcontractor characteristics to be considered in international projects should be revealed clearly. Accordingly, this paper proposes a structured process for subcontractor selection in international construction projects. Toward this aim, a questionnaire survey was applied to 96 construction companies, all of which are members of Turkish Contractors Association, and the corresponding numerical results were evaluated via descriptive statistics and 95\% confidence interval. Thus, a three-step selection procedure together with their specific criteria was suggested from the conceptual point of view. These steps include (i) shortlisting with ten criteria, (ii) negotiation with seven criteria, and lastly (iii) final selection with seven criteria. Hence, this study can provoke potential researchers to find similarities or differences of such criteria between their countries and Turkey. Also, it can help both main contractors to execute the whole construction process in a financially sustainable environment and subcontractors to increase business opportunities in the international market.
\end{abstract}

\section{Corresponding Author:}

Volkan Arslan, Department of Civil Engineering, Bulent Ecevit University, Incivez Mahallesi, Farabi Kampusu, 67100, Zonguldak, Turkey

Email: volkanarslan@beun.edu.tr

\section{Introduction}

Subcontracting is a recognized function of the construction industry. It refers to sub-letting some portions or complete units of the work in the total project to subcontractors. Since the physical capital investment and technology requirements are quite low for most subcontracting trades and an access to productive factors is an easy task, the entry barrier to the subcontracting business is minimum in the industry. In other words, the cost of entering the market is not high relative to other sectors. Many of these subcontracting companies do not have any necessary expertise to undertake a work satisfactorily and, as a consequence, are unable to give their clients a service they require. 
Subcontracting has also a significant aspect in executing construction activities in international projects which are generally performed in uncommon regions and conditions. In fact, this may lead to some unexpected risks. Thus, a main contractor's ability to select suitable subcontractors in international projects is a key competitive advantage [1]. However, in the literature, improvements in subcontractor selection criteria have not received the attention that one would expect from a significant contribution to the construction industry. Therefore, the present study aims to introduce subcontractor selection criteria in international construction investments.

\section{Materials and Methods}

The data presented in this study were obtained by a two-stage questionnaire survey that was given to members of Turkish Contractors Association [2]. First, a pilot survey was carried out with 30 members selected by random sampling to remove practical concerns on questions. After the pilot study, modifications were incorporated into the final version of the questionnaire. This sample group was selected because it is an accepted list of firms within the Turkish construction industry. Member firms of this Association perform approximately $70 \%$ of total investments made in Turkey, and have also undertaken $90 \%$ of the work done abroad in the field of construction. There are 139 members in total, of which 96 firms $(69.06 \%)$ positively responded to the survey request. The number of companies interviewed is statistically adequate $(\mathrm{n} \geq 30)$ to represent the whole. Furthermore, Babbie [3] suggested that any return rate over 50\% can be reported, that over $60 \%$ is good, and that over $70 \%$ is excellent. Respondents were contractors' professional managers who choose subcontractors. Interviews were conducted face-to-face at interviewees' offices and ranged from 1 to 2 hours, with each interview being tape-recorded. They were carried out in an open and semi-structured manner, allowing respondents to introduce whatever information was felt to be relevant. In order to make the interviewing more effective and to save the time of interviewees, respondents were briefed about overall objectives and the methodology of the survey before interviews through either (i) an e-mail or (ii) a telephone conversation. The fact that each company's business philosophy could guide the interviewee's personal opinion was also stressed.

The survey was statistically evaluated by the $95 \%$ confidence interval of results [4]. To this aim, respondents were asked to assign a value between 0 (extremely unimportant) and 100 (extremely important) to each stage of selection. For the analysis of this method, mean values and standard deviation were initially obtained. Upper and lower limits were then calculated. In order to apply these equations, SPSS (Statistical Package for Social Sciences) was used.

Demographic features of surveyed firms, including both respondents' characteristics and structures of construction companies, were revealed by survey results. Tender Managers made up $81.25 \%$ of participants and $18.75 \%$ were Chairmen of the Board of Directors. The statistical data indicated that participants had adequate business experience in the construction industry to answer the questionnaire satisfactorily. The mean work experience of respondents was 17.69 years, the standard deviation was 10.05 years, and the median was 13.5 years. Minimum and maximum values of the work experience were 7 and 36 years, respectively. A diversified group of decision makers who currently perform subcontractor qualifications participated in the study. Each participant had taken part in the selection process of at least one subcontractor, $25 \%$ had taken part in more than 50 selection processes, $18.75 \%$ had participated in fewer than 5 selections, $18.75 \%$ had been involved in 6-10 selections, $25 \%$ had been involved in 11-20 selections, and 12.5\% had taken part in 21-50 selections.

Besides individual characteristics of respondents, features of surveyed firms are also very important. Considering their average annual revenues, a vast majority of companies $(81.25 \%)$ can be considered as being in the large scale (> \$20 million) category while $6.25 \%$ of main contractors were middle scale firms $(\$ 10-20$ million) and $12.5 \%$ were small scale firms $(<\$ 10$ million $)$. The fact that large scale firms are likely to have high standards in terms of the internal organization and project characteristics both indicates the reliability of the survey and has led to further research projections for the future. Surveyed companies had undertaken foreign construction projects in more than one field of construction to date. According to types of international projects, $81.25 \%$ of main contractors had performed engineering projects (highways, bridges, harbors, tunnels, dams, and infrastructure). The fact that international projects are composed of engineering investments in general is an expected finding. In addition, $62.5 \%$ of companies had executed industrial investments (power plants, refineries, and pipelines) and $62.5 \%$ had completed building projects (residential, commercial, schools, hotels, and hospitals). This indicates that main contracting firms have not specialized in only one specific project type and that subcontracting has become an inevitable tool of trade contracting for main contractors in 
the international construction industry. Considering the firms' business experience, $18.75 \%$ of them had been in the global construction market for $1-5$ years, $25 \%$ for $6-10$ years, $6.25 \%$ for $11-20$ years, and $50 \%$ for more than 20 years. A significant portion of main contractors $(56.25 \%)$ have been undertaking international projects for more than 10 years. This points out that they have adequate experience in foreign markets. Another indicator of the surveyed firms' international experience is the number of projects undertaken abroad. Of firms, $18.75 \%$ had served as a main contractor in $1-5$ projects, $15.62 \%$ in $6-15$ projects, $15.62 \%$ in $16-25$ projects, and $12.5 \%$ in $26-50$ projects. The fact that $37.5 \%$ of main contractors had successfully completed more than 50 foreign projects is an important finding, which shows their widespread experience. Similarly, it was found out that main contractors had successfully concluded many large scale foreign projects. Considering the maximum size of the labor force, $12.5 \%$ of main contractors had employed fewer than 100 workers in a project, $18.75 \%$ had employed $100-500$ workers, $25 \%$ had employed $501-1000$ workers, $31.25 \%$ had employed 1001-5000 workers, and 12.5\% had employed more than 5000 workers. Firms had concurrently undertaken construction projects in three different continents. Former Soviet Countries (75\%), Middle East (62.5\%), and North Africa (43.75) are especially vital and strategic markets for Turkish construction companies.

\section{Subcontractor Selection Criteria}

The literature review was instrumental in the identification and the design of factors affecting the selection decision of main contractors about subcontractors in international projects. Respondents were also encouraged to add to the list any other criteria they considered to be important. Since subcontractors are a kind of contractor, factors used for the main contractor selection are also utilized. More criteria could have been taken into account in the model, and the complexity of the selection procedure could have been increased using additional evaluation techniques. However, criteria ignored by respondents in the pilot survey were not factored into the model to avoid negligible details. In fact, infinite numbers of criteria can be suggested without considering their importance weights in any decision problem. Conversely, restricting the number of evaluation variables to, for example, three or five is simply too few to run a robust, thorough, and reliable qualification. Another aspect for improvements of the model is the number of criteria. The number and importance of criteria used for contractors to select a good subcontractor during the tender evaluation may vary from one to another. For this reason, the present research concentrated on a set of 'standard' criteria. This may raise problems of 'inadequacy' and 'irrelevance' of criteria when implemented to different types of project. Nevertheless, an attempt has been made to select and find the most 'suitable' set of criteria via a survey.

In most instances, the sole deciding factor is the tender amount, and subcontractors that do not meet price requirements are excluded from further consideration. Because of the considerable weight which most contractors attach to price, the influence of other factors is 'hidden' in reality. However, if price alone dominates the specialist selection, then it is unlikely that requirements of a small subcontracting firm and a main contractor will be satisfied because this behavior (that is, single criterion decision making) is not conducive to harmonization and good relationships between two parties, which is in turn resulted in a poor project performance. As such, relying singularly on tender price alone can be fatal as the capability of the tenderer may not be adequately assessed. A single criterion cannot give a full expression of goals pursued by various contractors. In other words, taking solely cost figures into account raises quality problems during and upon the completion of the project. However, the lowest tender price tends to attract a contractor's interest as superior to other criteria, and thereby, some contractors simply award contracts to lowest tenderers for the sake of cost savings. Subcontractors are forced to make a profit by providing the 'cheapest' possible construction, and 'low bid' based selections have been common. In practice, generally subcontractors who submit lowest tender prices obtain subcontracts. However, the lowest tender may not necessarily deliver prompt and good quality works. Awarding contracts to low bidders usually results in a poor performance in terms of quality and excessive delays. This means that a price that is too low likely inhibits the attainment of contractor's other objectives of quality and speed. Most of such cases end up in litigation. As a result, selecting the lowest bidder in a sealed tender auction can sometimes result in serious performance problems after the contract is awarded. Moreover, stiff competition causes subcontractors to cut their margins to get jobs and subcontractors trying to win a contract often lower the bid price. In fact, lower profit margins bring higher risks and lower levels of quality. Outcries against substandard construction (for example, in Turkey) or escalating construction claims have been often traced to the selection of lowest priced tenders. Another 
disadvantage of using the lowest bid as a principal discriminating criterion is that some subcontractors (e.g., those facing a shortage of work) may enter unrealistically low bid prices. Namely, low bids as the sole criterion for selection encourage unqualified subcontractors to submit bids. Of course, competitions are expected to drive costs down, but a low price cannot ensure quality standards expected by a contractor, because a subcontractor can reduce costs at the expense of the product's quality or can desperately quote low prices by reducing their quality of work. It means that low price awards motivate subcontractors to provide minimally acceptable construction products and that a low bidder can become a very expensive proposition. The practice of awarding tenders on a basis of the low tender price eventually will lead to ultimate quality problems. Therefore, a best value procurement should focus on selecting a suitable subcontractor with an offer that is most advantageous to a contractor when price and other important factors are appropriately combined. In terms of public investments, however, public clients have to aim to demonstrate the accountability for public funds and even-handedness to suppliers and contractors.

Characteristics of subcontractors and guidelines in the selection procedure examined in this study are largely based on subjective rather than objective criteria, as explained in detail as follows. Since the model developed as illustrated in Figure 1 suggests three different stages as shortlisting, negotiation, and final selection, all criteria were classified according to these groups. Such a three-tier tendering structure prevents subcontractors bidding for subcontracts outside their capabilities. 


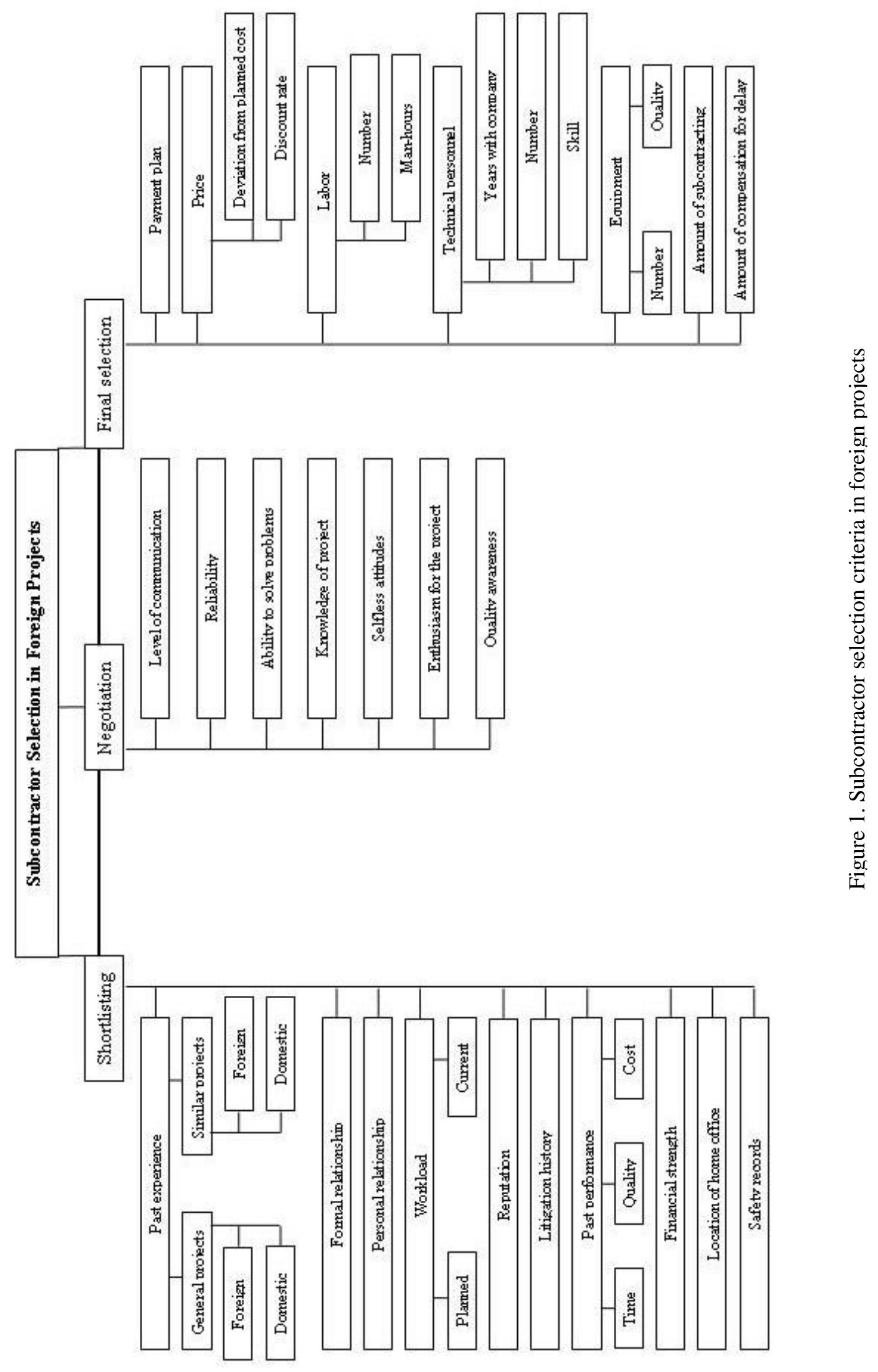




\subsection{Shortlisting criteria}

This initial appraisal step is a preliminary vetting or restricting process of potential subcontractors. It is therefore preferable to identify those subcontractors deemed to satisfy project requirements and only then invite them to submit a tender. In other words, a pre-tender screening allows a contracting authority to sort potential operators into those of high and low expected quality before the tendering actually takes place. Such separation is important because if low and high quality subcontractors bid simultaneously, difficulties will arise in distinguishing low bids that are due to cost efficiency from those that involve the reduced quality of service. In this phase, basic characteristics of candidates on their professional backgrounds are considered in particular. Aims of this pre-tender process used to investigate and to assess capabilities of subcontractors to carry out a subcontract satisfactorily if it is awarded to them are as follows:

- to determine the possible subcontractor's competence, ability, skill, and efficiency for participating in the project bid and thereby for providing an early warning of the subcontractor's likely performance,

- to remove the risk of the project failure,

- to minimize the amount of the unrealistic tendering of incapable subcontractors,

- to filter out incompetent subcontractors from the bidding process quickly and thus to identify subcontractors with whom a main contractor could enter into a subcontract. Also note that main contractors disqualified from bidding for a project in their own capacities due to prequalification criteria in the international bidding often end up as subcontractors,

- to minimize the possibility of the subcontractor default, together with the cost and time involved in the bidding. It is worth noting that costs of the bidding incurred by potential subcontractors are sunk - they cannot be recovered if the bid is unsuccessful. Hence, by screening out subcontractors who are unlikely to be selected irrespective of their bid prices, total sunk costs can be significantly reduced.

In the shortlisting stage, subcontractors are first invited to submit their bids. Information about criteria 'past experience', 'workload', 'financial strength', 'location of home office', and 'safety records' is obtained from firms wishing to be included on the project tendering list via an application form from the main contractor. For information concerning criteria 'reputation', 'litigation history', and 'past performance', main contractors and subcontractors that have previous working relationships with the related subcontractor are contacted. 'Formal relationship' and 'personal relationship' are evaluated by means of the main contractor's own experience. Candidates must get through this step to be eligible for second and third phases of the selection. Related tender documents of the package such as drawings and specifications are then given to qualified candidates. To find out the importance level of this first stage, respondents gave numerical weights between 0 (extremely unimportant) and 100 (extremely important). As can be seen from Table 1, main contractors assigned a weight of 69.69 as a mean value. Considering other two stages, shortlisting is the least important stage.

Table 1. Importance weight of the shortlisting stage

\begin{tabular}{cccccccc}
\hline Mean & $\begin{array}{c}\text { Standard } \\
\text { deviation }\end{array}$ & $\begin{array}{c}\text { Minimum } \\
\text { value }\end{array}$ & Median & $\begin{array}{c}\text { Maximum } \\
\text { value }\end{array}$ & Error & \multicolumn{2}{c}{$\% 95$ confidence interval } \\
\hline 69.69 & 22.54 & 25 & 70 & 100 & 5.64 & 57.67 & 81.70 \\
\hline
\end{tabular}

\subsection{Negotiation criteria}

In this step, candidates on the approved list are first interviewed. This and other two stages are executed by a selection committee including project manager, site manager, and other technical managers. To avoid individual biases, it is recommended that a minimum of three evaluators is required for each scoring activity. To come to a conclusion, it is aimed to make a group decision. Before proposal meetings, subcontractors submit their detailed project proposals and thus the committee has an opportunity of pre-appraisal. The related information should always be treated as a matter of utmost confidentiality. An importance weight of 72.81 was suggested for this stage by participants, as can be seen in Table 2 . 
Table 2. Importance weight of the negotiation stage

\begin{tabular}{cccccccc}
\hline Mean & $\begin{array}{c}\text { Standard } \\
\text { deviation }\end{array}$ & $\begin{array}{c}\text { Minimum } \\
\text { value }\end{array}$ & Median & $\begin{array}{c}\text { Maximum } \\
\text { value }\end{array}$ & Error & \multicolumn{2}{c}{$\% 95$ confidence interval } \\
\hline 72.81 & 26.27 & 15 & 72.5 & 100 & 6.57 & 58.82 & 86.81 \\
\hline
\end{tabular}

\subsection{Final selection criteria}

More specialized factors directly related with the project to be awarded are examined in this third stage whereas general capability levels of candidates are determined in former two stages. Therefore, 'final selection' is perceived as the most important stage by main contractors in the industry. A clear indicator of this judgment is that the mean value of the importance weight for this stage was calculated as 79.69, as given in Table 3. First steps of this stage are executed together with the negotiation stage. Respondents assigned a weight of 79.69 as a mean value. Given all three stages, the final selection was found to be the most significant stage.

Table 3. Importance weight of the final selection stage

\begin{tabular}{cccccccc}
\hline Mean & $\begin{array}{c}\text { Standard } \\
\text { deviation }\end{array}$ & $\begin{array}{c}\text { Minimum } \\
\text { value }\end{array}$ & Median & $\begin{array}{c}\text { Maximum } \\
\text { value }\end{array}$ & Error & \multicolumn{2}{c}{$\% 95$ confidence interval } \\
\hline 79.69 & 26.68 & 20 & 90 & 100 & 6.67 & 65.47 & 93.90 \\
\hline
\end{tabular}

\section{Conclusions}

This paper presents a structured selection process for subcontractors to take part in international construction investments. In conclusion, a three-step selection procedure and their criteria was determined. The steps are composed of (i) shortlisting of ten criteria, (ii) negotiation of seven criteria, and (iii) final selection of seven criteria. Also, it was found out that the final selection was found to be the most significant stage, followed by negotiation and shortlisting, respectively. Consequently, this research can have considerable implications on potential researchers, main contractors, and subcontractors.

\section{Acknowledgements}

The authors gratefully acknowledge numerous chairpersons, managers, and other technical/administrative staff of surveyed companies for their generous collaboration and contributions. The authors also would like to thank financial supports provided by Committees on Research Grants of Bulent Ecevit University and Akdeniz University.

\section{References}

[1] S. Ulubeyli and A. Kazaz, "Fuzzy multi-criteria decision making model for subcontractor selection in international construction projects," Technological and Economic Development of Economy, vol. 22, pp. 210-234, 2016.

[2] S. Ulubeyli, "Fuzzy multiple criteria decision making model for subcontractor selection in international construction projects," Ph.D. thesis, Istanbul University, Istanbul, Turkey, 2008.

[3] E. Babbie, The Practice of Social Research, 11th ed., Belmont, USA: Wadsworth Publishing, 2007.

[4] J. Curwin and R. Slater, Quantitative Methods for Business Decisions, 3rd ed., London, England: Chapman and Hall, 1992 


\section{BIBLIOGRAPHY OF AUTHORS}

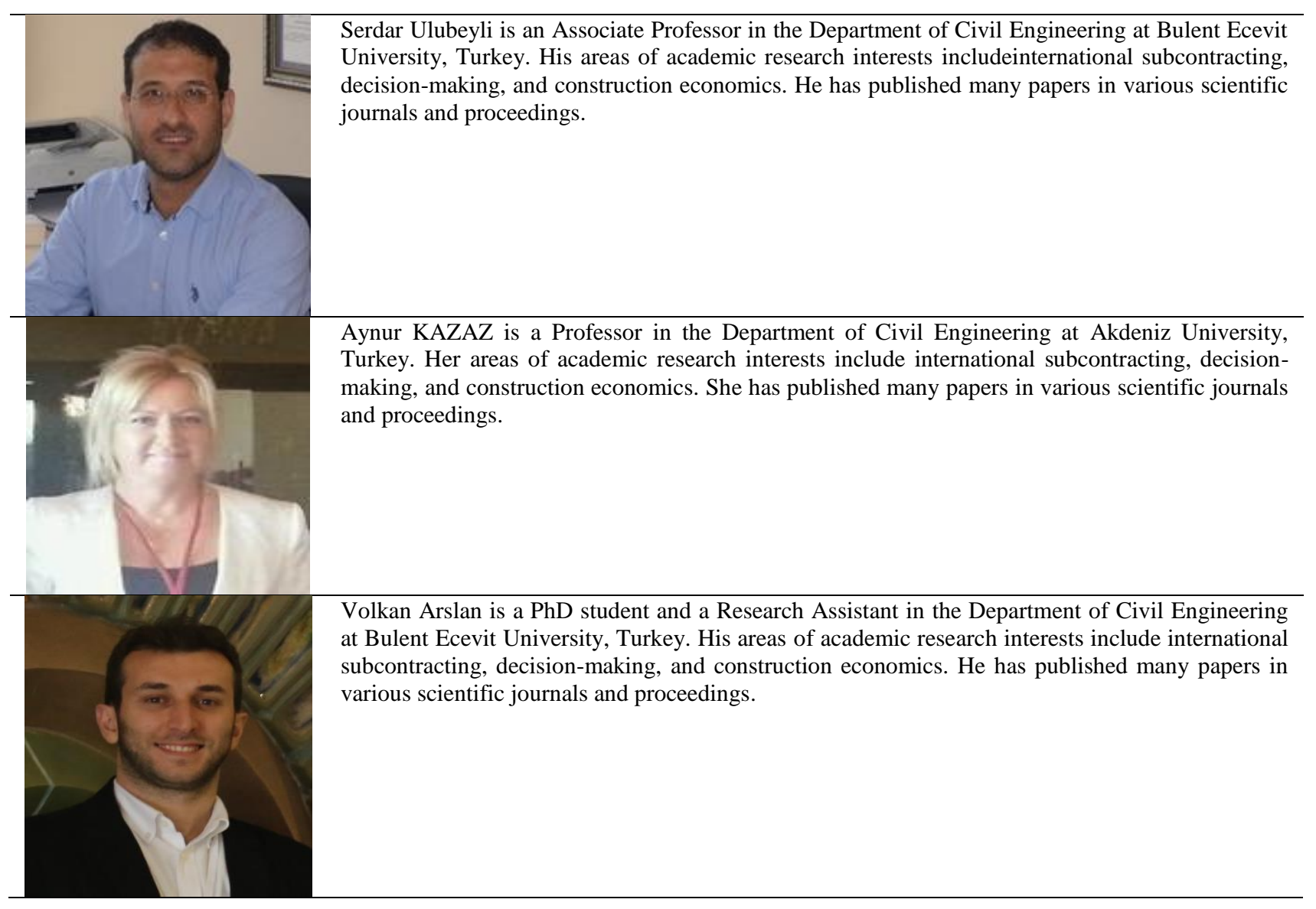

